Research Article

Open Access

\title{
Review of a Physician HIV Training Program for Pediatric Providers
}

\author{
Sarah Elizabeth Davey ${ }^{1 *}$, Michael Koster ${ }^{1}$, Marie Lina Excellent ${ }^{2}$ and Jacqueline Gautier ${ }^{2}$ \\ ${ }^{\prime}$ Department of Pediatric, Brown University, Providence, RI 02912, USA \\ ${ }^{2}$ Saint Damien Pediatric Hospital, USA
}

\section{Article Info}

\section{*Corresponding author: Sarah Elizabeth Davey \\ Department of Pediatric Brown University \\ Providence, RI 02912 \\ USA \\ E-mail: sarah_davey@brown.edu}

\section{Received: August 5, 2015 \\ Accepted: August 17, 2015 \\ Published: August 24, 2015}

Citation: Davey SE, Koster M, Excellent ML, Gautier J. Review of a Physician HIV Training Program for Pediatric Providers. Madridge J AIDS. 2015; 1(1): 1-8.

doi: $10.18689 / \mathrm{mja}-1000101$

Copyright: (c) 2015 The Author(s). This work is licensed under a Creative Commons Attribution 4.0 International License, which permits unrestricted use, distribution, and reproduction in any medium, provided the original work is properly cited.

Published by Madridge Publishers

\begin{abstract}
Background: Haiti is one of the most severely resource-constrained countries in the Americas, experiencing high rates of HIV. Access to HIV care is the paramount barrier with a paucity of specialized care providers throughout the very rural country. As of 2012 , about 150,000 out of a population of 10 million living in Haiti (1.5\% prevalence) were HIV-positive, with 12,000 of 3.6 million children under the age of 14 years old ( $0.3 \%$ prevalence).
\end{abstract}

Study Purpose: The HIV Training Program for Physicians at St Damien Hospital (HIVTP), established in December 2008, is supported with hospital funding and additional support from the United States President's Emergency Plan for AIDS Relief. We evaluated the effect of the training model in expanding the human resource pool for pediatric HIV care, as well as participant satisfaction.

Methods: A total of 42 providers have been trained by the HIVTP as of September 2014. A survey organized into questions regarding program length, lecture content, lecture modalities, and current engagement in pediatric HIV care was distributed to all graduates. Results were analyzed by computing frequencies of survey responses. Preand post-test assessments of knowledge that were administered to program participants were evaluated as markers for participant improvement. A focus group was held among program staff and administrators to collect qualitative data regarding program structure and modalities. Quantitative and qualitative results were cross-analyzed in order to assess the effect of the program in expanding human resources for pediatric HIV in Haiti.

Results: Out of the 42 surveys administered, a total of 14 were completed and returned, for a response rate of $33 \%$. Of the respondents, $79 \%$ of HIVTP participants continue to practice pediatric HIV care in Haiti. Trainee satisfaction of the program, measured by survey responses to agreement with questions about topic content and length, was $86 \%$. Program pre- and posttest results indicated a positive improvement in knowledge after the program. Focus group and survey results indicated that there should be revisions in program length and modality, preferably through a mixed methods model including case-based, hands-on, and online modalities.

Conclusion: There was a high rate of HIVTP trainee respondents who are currently providing care for pediatric HIV in Haiti with an overall high satisfaction rate of participants. Revisions to program modality and length could strengthen the effect of the program. Better retention of graduates and improving focus on task shifting could help to decentralize delivery and contain costs.

Keywords and Abbreviations: ART: Antiretroviral therapy; GDP: Gross Domestic 
Product; HIVTP: HIV Training Program at St. Damien; MOH: Ministry of Health; PEPFAR: President's Emergency Fund for AIDS Relief; PMTCT: Preventing Mother to Child Transmission; SDH: St. Damien Pediatric Hospital; TB: Mycobacterium tuberculosis; UNAIDS: Joint United Nations Program on HIV/ AIDS; WHO: World Health Organization

\section{Background}

Human resources training programs have a history of expanding the continuum of Human Immunodeficiency Virus (HIV) care. In current literature, most training programs have followed a task-shifting model of transferring the burden of care from a small pool of physicians to a larger pool of specially trained nurses and other allied health professionals. In 2011, the South African Ministry of Health (MOH) rolled out a task-shifting model of care that certified nurses to administer ART for HIV positive patients.

While skeptics believed that human resource limitations, lack of clinical mentorship, infrastructure challenges, and poor drug supply would be insurmountable challenges, the project was initiated with the goal to have nurses initiate ART and manage successive treatment. Despite these challenges, a 2014 before-after cross-sectional study that looked at patient charts of adult ART clinics and self-assessments was undertaken to evaluate the effectiveness of South Africa's new model of care. The study found that the new model of care resulted in the majority of ART initiation cases being managed by nurses, along with an improvement in the quality of care provided by South African nurses. The results of this study suggested a successful implementation of a task-shifting model of care through an $\mathrm{MOH}$ sponsored program [1]. This nurse-based, doctor-supported model of care established by the South African $\mathrm{MOH}$ demonstrated it is possible to decentralize administration of ART through nurse-initiated and managed ART in more remote townships where referral hospitals and subspecialty physicians are not readily available.

Public-private partnerships are also a powerful method for addressing the human resources issue in HIV/AIDS. The effort by the United States President's Emergency Plan for AIDS Relief (PEPFAR) to expand pediatric HIV care in highburdened and resource-constrained settings is a strong example of the power behind public-private partnerships in public health. PEPFAR works with the support of national governments and other international organizations in order to expand HIV care for infected pregnant women, increase access to early infant diagnosis for HIV-exposed infants, increase human resource capacity through training and resources to clinicians providing pediatric care, and to form public private partnerships with pharmaceutical companies for increased access to effective medicines at low cost $[2,3]$.

In order to scale-up pediatric HIV care quickly and effectively, PEPFAR began by funding and partnering with local governments and other private international organizations in order to establish a family-centered approach to service delivery in 15 focus countries [2,3]. As of 2010, it was reported that $84 \%$ of children estimated to be receiving antiretroviral therapy (ART) were a direct result of PEPFAR support [2]. While there is a need for more physicians, in order to scale-up care, more nurses and field workers also need to be trained for successful task shifting; defined as the transfer of stable, clinical duties from a physician to a specially trained health worker. This can be established through the training of clinical staff on ART delivery, such as what has been established through the scale-up of PEPFAR, and task shifting from physicians to nurses and field workers [2]. Studies performed in Sub-Saharan Africa on decentralization of pediatric HIV care have argued that, in order to reduce the gap between need and delivery of care for children, there needs to be a geographical expansion of services from large urban health care facilities to smaller, rural health facilities where most of the primary care for children in low-resource settings is provided. Testing and treating earlier in the trajectory of HIV infection can lead to a better prognosis and improvement in quality of life. Early and consistent delivery of ART therapy can be cost effective because patients are identified and treated before presenting with costly work-ups and treatments for opportunistic infections. Increasing the number of HIV care providers available in low-resource settings will not only improve access, testing and diagnosis, but also create better drug adherence and retention of care through more readily available clinicians [1,4-6].

Haiti is one of the most severely resource-constrained countries in the Americas, ranking $207^{\text {th }}$ in the world in gross domestic product (GDP) per capita. The World Bank has estimated that about $68 \%$ of the Haitian population is affected by poverty and $47 \%$ by extreme poverty [7]. Haiti experiences the highest rates of HIV in the Caribbean, due in part to a lack of HIV-specialized care providers throughout the mostly rural country [7]. HIV prevalence among pregnant women averages $3.1 \%$ in 2003 and ranges between $0.8 \%$ in Haiti's western rural parts, to upwards of $11.8 \%$ in urban areas $[6,8]$. Most HIV positive children were infected through maternal to child transmission, with vertical transmission rates reported up to 27-37\%. Without proper ART monitoring by trained healthcare professionals, transmission rates, particularly from mother to child, will fail to deflate [4]. Although Haiti has seen a great improvement in access to ART care over the past decade, gaps remain in receipt of care. Less than $5 \%$ of the recipients of HIV care were children, with delivery impeded by barriers such as standardized treatment initiation, poor pediatric drug formulations, complexity of pediatric ART dosing, inadequate prevention of maternal to child transmission (PMTCT), lack of pediatric diagnostic methods especially for early infant diagnosis, family/social challenges, and, most importantly, a shortage of pediatric care providers [4,6-8]. In 2006, Haiti adopted national HIV treatment guidelines, which moved the country towards a uniform standard of care, but with a physician density of only 0.25 per 1,000 provider shortage remains a critical need $[6,7]$.

St. Damien Hospital for children (SDH) has the largest medical training program for pediatric HIV care in Haiti and 
has the potential for significant impact on the number of HIVspecialized physicians throughout the country [4]. In 2007, SDH began routine HIV testing of all patients (both in- and out-patients), a fundamental first step in managing high rates of HIV. The HIV Training Program for Physicians at St. Damien Hospital (HIVTP) was established in December 2008, with hospital funding and additional support from PEPFAR [2,3]. With the mission to support children at risk for HIV, the HIVTP assisted in the expansion of support throughout the country by training physician providers in HIV/AIDS care delivery. The setting for the HIVTP is the HIV clinic at SDH, a premier treatment center with over 400 children on ART. The HIVTP trainers are comprised of one general physician, five pediatricians, one psychologist, two social workers, and one pharmacist. The program operates as a training course that combines theoretical and practical sessions in both the outpatient HIV clinic, as well as admitted patients with HIV at $\mathrm{SDH}$. Operating over the course of a six-week period, the first two weeks cover general pediatrics (for general physicians only) and the final four weeks cover topics regarding pediatric HIV care (all HIVTP participants, including pediatricians). The goal of the HIVTP is to narrow the gap between need and delivery of pediatric HIV care by creating a larger base of HIVspecialized trained clinicians that span across a wider geographical setting.

This study aims to identify the effect of the Saint Damien HIVTP in increasing the human resource pool for pediatric HIV in Haiti. We hypothesize that the HIVTP has been successful in meeting the objective of increasing the number of pediatric HIV providers practicing in Haiti. Within this study, the primary outcome is defined as the number of HIVTP physicians who continue to practice pediatric HIV care out of the total number of physicians trained in the program. A secondary aim of the study includes measuring HIVTP participant satisfaction with the program through a structured survey, assessing knowledge improvement through pre- and post-test scores, and identifying barriers and areas for improvement through focus group discussion with program administrators and facilitators. Suspected barriers to providers being able to deliver care include: poor access to the internet and technology, budget and funding constraints, and time limitations. Although this particular study focuses on a training program specifically for physicians, it is intended to support the research for expanding human resources for health across multiple disciplines.

\section{Methods}

Methodologies were three-fold with collection of survey responses, program test data, and focus group responses.

\section{Study Site}

After IRB approval at both sites, researchers travelled to $\mathrm{SDH}$ in Tabarre, Haiti to conduct a program follow-up and evaluation of the HIVTP with trainers, key clinic staff and the graduates of the program. Although PEPFAR has provided funding to multiple training sites throughout the country of
Haiti, this study specifically focuses on the data collected at the SDH site. HIVTP applicants, however, were drawn from every region in Haiti and were not restricted to the Tabarre and Port-au-Prince areas.

\section{Study Participants and Methods}

As of September 2014, a total of 42 providers had been trained by the HIVTP. The structured survey was distributed to all 42 program graduates. Demographic data was collected from each participant, including region of residence. All available pre- and post-test data (e.g. program statistics) were assembled into a single database for analysis. All HIVTP trainers, as well as the Executive Director of SDH and a program manager for Plan National, the Haitian branch of PEPFAR were included in the qualitative focus group discussions.

Through an updated registry of program participants, researchers distributed a program survey (translated into French) to each of the 42 graduates by email. In addition, researchers also asked for continued participation in the project including involvement in the focus group, and willingness to answer follow-up emails. After two unsuccessful e-mail attempts, a native speaker and program facilitator attempted to administer the survey verbally via telephone. If an individual was unable to be reached through the contact information listed after program completion, investigators in conjunction with Haitian staff reached out to hospitals and clinics where they were last known to have worked. After all of these efforts failed, the participant was coded as a nonresponder.

Content of the structured survey was organized into four domains: questions regarding total length of the program (e.g. impact on time away from clinical responsibilities outside of the HIVTP), topic content of the program and extent of lecture coverage (e.g. PMTCT, co-infections, malnutrition), lecture modalities (e.g. computer based vs. in-person), and current engagement in providing pediatric HIV care.

Effect of the training program was determined by measures of the intended outcomes of the training program. The primary outcome measure was whether physicians were currently treating patients with HIV in their practice. These questions included whether or not the physician currently treats HIV patients, percentage of eligible pregnant patients on ART, percentage of eligible pediatric patients on ART, and whether or not the physician also treats Mycobacterium tuberculosis (TB) co-infection.

Trainee satisfaction was measured by levels of satisfaction with varying aspects of the training program. This was evaluated by calculating the average frequency of responses as "just right" (within a spectrum ranging from "too short" to "too long" to questions regarding program length and amount of time spent on each topic). In addition, questions asking trainees whether or not they felt prepared to take care of pediatric HIV cases and to train other members of their team on pediatric HIV practices were tallied. 
Post-training competency was evaluated using the preand post-test scores that were collected from tests given at the start and finish of each training session. For each program session with available test data, an average was calculated for all pre-tests, posttests, and practical exams. In addition, average testing improvement for each session was calculated by the percentage improvement from the pre-test to the post-test. Calculation of individual improvement scores was not possible, due to the anonymity of the test score records.

All program administrators and facilitators were invited to participate in the focus group, which was held in the conference room of the HIV clinic at SDH. A native Haitian facilitated the focus group, with fluency in both French and Haitian Creole. Although all of the focus group participants spoke fluent French, it was necessary to have a native Haitian Creole speaker as a facilitator in order to interpret dialect. Notes were taken during the focus group by the Haitian facilitator and the primary investigator, as well as an audio recording. Questions were asked on the following topics: how program participants are selected, how program administrators measure the success of the program, how the program administrators keep in touch with past participants, what the biggest successes of the training program have been, what the main barriers and areas for improvement to the program are, what the protocol is for program revisions, opinions on lecture modality, and what opportunities the program has for expanding to include online modules.

\section{Data Analysis}

\section{Survey Analytic Methods}

Survey results were collected, organized, and recorded into an electronic database. Once the survey return period had ended, the data were imported into statistical software (Stata/se ${ }^{\mathrm{TM}}$, StataCorp TX, USA) for analysis. Researchers used the data set to run frequencies across the survey variables for quantitative results.

\section{Focus Group Analytic Methods}

Focus group responses were recorded into a chart and organized by question and individual responses. Responses were then organized into the following categories: preferred learning method preferred teaching module, opinions on program length, and ideas for program adjustment. Then, using frequencies from survey responses to questions of the same topics, the results were compared.

\section{Results}

\section{Analytic Sample}

Of the 42 distributed surveys, 14 were completed and returned to the training program administrator, reflecting a $33 \%$ response rate with 10 participants unreachable. Of the 14 returned surveys, eight responded to the first e-mail attempt, three responded to the second e-mail attempt, and three responded after a telephone reminder. The majority of program participants who returned surveys reside in either the Nord (36\%) or Sud (21\%) regions of Haiti, with at least one participant from seven of the ten regions (Table 1).

Table 1: Frequency of HIVTP participants by region in comparison to HIV prevalence by region.

\begin{tabular}{|l|l|l|l|}
\hline & $\begin{array}{l}\text { Frequency of HIVTP } \\
\text { participants }\end{array}$ & $\begin{array}{l}\text { Prevalence of } \\
\text { participants within } \\
\text { HIVTP }\end{array}$ & HIV Prevalence \\
\hline District & & & \\
\hline Artibonite & 2 & $14.3 \%$ & $2.03 \%$ \\
\hline Grand'Anse & 1 & $7.14 \%$ & $1.35 \%$ \\
\hline Nippes & 1 & $7.14 \%$ & $2.3 \%$ \\
\hline Nord & 5 & $35.71 \%$ & $2.03 \%$ \\
\hline Nord-Est & 1 & $7.14 \%$ & $3.3 \%$ \\
\hline Ouest & 1 & $7.14 \%$ & $2.37 \%$ \\
\hline Sud & 3 & $21.43 \%$ & $1.72 \%$ \\
\hline
\end{tabular}

\section{Training Program Efficacy}

Training program efficacy was evaluated and compiled into table 2. Of the 14 participants who returned completed surveys, $79 \%(11)$ were currently treating HIV patients and $21 \%(3)$ reported not treating HIV patients. Of the 14 participants, 40\%(8) care for children, adolescents, adults, and pregnant women in their practice: $15 \%$ (3) primarily care for children and $15 \%(3)$ primarily care for adolescents. Of the eight physicians who were currently treating pregnant women, $63 \%(5)$ reported that more than $75 \%$ of their patients with HIV were on ARVs. Of the eight physicians who treated children or infants, $38 \%(3)$ reported that more than $75 \%$ of their pediatric patients were on ARVs and $50 \%(4)$ reported that less than $9 \%$ of their pediatric patients were on ARVs. Additionally, 43\%(6) of the 14 physicians treated TB coinfections in their clinics. Physicians who completed the HIVTP currently provide care for a range in number of HIV patients, with about half caring for 100 patients or fewer and half caring for more than 100 patients in their clinics.

Table 2: Training program efficacy measured in frequencies of current pediatric HIV care practices.

\begin{tabular}{|l|l|l|}
\hline & Frequency & Percent \\
\hline Currently treating HIV patients & & \\
\hline No & 3 & $21.4 \%$ \\
\hline Yes & 11 & $78.6 \%$ \\
\hline Number of Patients & & \\
\hline $0-50$ & 4 & $28.6 \%$ \\
\hline $51-100$ & 3 & $21.4 \%$ \\
\hline $101-200$ & 4 & $28.6 \%$ \\
\hline More than 200 & 3 & $21.4 \%$ \\
\hline Provide care to & & \\
\hline Adolescents & 3 & $15 \%$ \\
\hline Adults & 5 & $25 \%$ \\
\hline Children/Infants & 3 & $15 \%$ \\
\hline Pregnant Women & 1 & $5 \%$ \\
\hline All of the above & 8 & $40 \%$ \\
\hline $\begin{array}{l}\text { If treating pregnant women, percentage of } \\
\text { patients on ART }\end{array}$ & & \\
\hline$<9 \%$ & 2 & $25 \%$ \\
\hline $10-25 \%$ & 1 & $12.5 \%$ \\
\hline $51-75 \%$ & 0 & 0 \\
\hline$>75 \%$ & 5 & $62.5 \%$ \\
\hline $\begin{array}{l}\text { If treating children and infants, percentage } \\
\text { of patients on ART }\end{array}$ & & \\
\hline$<9 \%$ & 4 & $50 \%$ \\
\hline $10-25 \%$ & 0 & 0 \\
\hline $51-75 \%$ & 3 & $57.5 \%$ \\
\hline$>75 \%$ & 8 & \\
\hline Do you treat tuberculosis? & & \\
\hline Yes & 3 & \\
\hline No & 3 & \\
\hline
\end{tabular}




\section{Trainee Satisfaction}

Overall trainee satisfaction with program length and topic coverage was good with $86 \%$ reporting "just right" (Tables 3). Of the 14 who returned surveys, $79 \%(11)$ reported that they were "absolutely" prepared to take on their own pediatric HIV cases following the training. However, of the 14 respondents, $100 \%$ reported that they felt "somewhat" prepared to train other members of their team in pediatric HIV management.

Table 3: Trainee Satisfaction measured in response frequencies to questions on program length and topic coverage.

\begin{tabular}{|l|l|l|}
\hline & Frequency & Percent \\
\hline Program Length & & \\
\hline Just Right & 9 & $64.3 \%$ \\
\hline Topic Coverage & & \\
\hline General Pediatrics & 14 & $100 \%$ \\
\hline Just Right & & \\
\hline Tuberculosis & 12 & $85.7 \%$ \\
\hline Just Right & & \\
\hline Malnutrition & 13 & $92.9 \%$ \\
\hline Just Right & & \\
\hline Preventing mother to child transmission & 13 & $92.9 \%$ \\
\hline Just Right & & \\
\hline CD4 Count Monitoring & 10 & $71.4 \%$ \\
\hline Just Right & & \\
\hline Medication Adherence & 12 & $85.7 \%$ \\
\hline Just Right & 83 & $86.3 \%$ \\
\hline Overall Trainee Satisfaction & & \\
\hline $\begin{array}{l}\text { After the program, I felt prepared taking } \\
\text { care of pediatric HIV patients: }\end{array}$ & & \\
\hline Not at all & 0 & 0 \\
\hline Somewhat & 3 & $21.4 \%$ \\
\hline Neutral & 0 & 0 \\
\hline Mostly & 0 & 0 \\
\hline Absolutely & 11 & $78.6 \%$ \\
\hline $\begin{array}{l}\text { After the program, I felt prepared to teach pediatric } \\
\text { HIV-care practices to members of my team }\end{array}$ & & 0 \\
\hline Not at all & 0 & \\
\hline Somewhat & 14 & 0 \\
\hline Neutral & 0 & \\
\hline Mostly & 0 & \\
\hline Absolutely & & \\
\hline & & \\
\hline
\end{tabular}

Of the 18 survey question responses (some respondents selected more than one response), 61\%(11) indicated that their preferred lecture modality was "in-person," with $22 \%(4)$ indicating "computer-based" and 17\%(3) indicating, "published lectures." There were 23 responses to learning methods preferences distributed as follows: $26 \%(6)$ preferring "formal lecture," followed by 22\%(5) preferring "online learning modules," 22\%(5) preferring "small group learning," $17 \%(4)$ preferring "formal lecture," and 13\%(3) preferring "case-based" learning. All 14 respondents (100\%) indicated that they would be interested in an advanced HIV training program if it were to be offered (Tables $5 \mathrm{~A}$ and $5 \mathrm{~B}$ ).

\section{Post-Training Competency}

Pre- and post-test results were available for four sessions (March-April 2012, June-July 2012, February-March 2014, and April-May 2014), with a total of 17 participants. The mean pretest score for all four of the training sessions with available data was 44\% (Range=30.9-60.1), the mean post-test score was $78 \%$ (Range $=59-86.5$ ), and the average improvement between pre- and post-tests was 34\%. Each session indicated a positive improvement between pre-test and post-test and all except for one session had a post-test average of $60 \%$ or higher (Table 4).

Table 4: Post-training competency measured through mean pre-test and post-test scores per training session.

\begin{tabular}{|l|l|l|l|l|l|}
\hline $\begin{array}{l}\text { Year of } \\
\text { Completion }\end{array}$ & $\begin{array}{l}\text { Class } \\
\text { Size }\end{array}$ & $\begin{array}{l}\text { Pre-Test } \\
\text { Average (\%) }\end{array}$ & $\begin{array}{l}\text { Post-Test } \\
\text { Average (\%) }\end{array}$ & $\begin{array}{l}\text { Average } \\
\text { Improvement (\%) }\end{array}$ & $\begin{array}{l}\text { Practical Exam } \\
\text { Average (\%) }\end{array}$ \\
\hline Mar-Apr 2012 & 5 & 39.34 & 66.2 & 26.9 & 75.6 \\
\hline Jun-Jul 2012 & 4 & 52.2 & 87.9 & 35.7 & 80.4 \\
\hline Feb-Mar 2014 & 3 & 35.8 & 59.8 & 24.0 & 62.3 \\
\hline Apr-May 2014 & 5 & 47.3 & 93.2 & 45.9 & 76.9 \\
\hline TOTAL & 17 & 44.1 & 78.1 & 34.0 & 74.8 \\
\hline
\end{tabular}

\section{Focus Group Results (Tables 5A and 5B)}

There were six participants in the HIVTP focus group overall. This included an SDH administrator, HIV clinic administrator, HIVTP director, pharmacist, psychologist, and social services coordinator (among whom one was a pediatrician and two were pediatric infectious diseases physicians).

\section{Methods for Measuring Program Success_}

Focus group participants indicated that the methods they had in place prior to this study for measuring program success were a satisfaction survey sent out to all program participants upon completion and the analysis of pre- and post-test data scores in order to predict overall knowledge improvement.

\section{Biggest Successes of the HIVTP}

Participants in the focus group were able to articulate several successes of the HIVTP. A couple focus group participants indicated that SDH saw a general increase in HIV/ AIDS knowledge among program and hospital staff due to the training program. Another comment was added that HIVTP participants were also more capable of understanding the implications and severity of HIV status of the patients that they see in their own clinics and were able to provide more comprehensive HIV care. Two focus group participants indicated that the training program has been the basis for a stronger referral system for infectious disease physicians and specialized pediatricians at SDH. They indicated that the SDH program's success has drawn international attention, including visiting doctors and expert lecturers who could provide additional insight and topic content. The general consensus was that the HIVTP has improved recognition for SDH both locally and globally for providing premier pediatric HIV care.

\section{Areas for Program Improvement}

All focus group participants indicated that the length of the HIVTP (six weeks; two weeks of Pediatrics (General Practitioners only) and four weeks of Pediatric HIV care) is too short and does not provide adequate time to cover both general pediatric care topics and HIV topics, meaning that there is less time for hands-on practice. On the other hand, having a six-week long training program makes it difficult to schedule SDH physicians to facilitate sessions and lectures, due to the fact that it requires they take time away from their own patients and schedule coverage of their duties. 
Questions were asked of participants in the focus group regarding whether or not they believed that the program would benefit from a mixed-module learning method. Participants in the focus group were hesitant to endorse anything involving an online module due to the poor internet capacity in Haiti, and that the cost of ensuring all program participants had access would be too high. One focus group participant indicated that the target participants are doctors who work with underserved populations, meaning that they especially may have unreliable access to the internet while working in those areas.

Table 5A: Focus Group Results.

\begin{tabular}{|c|c|c|c|c|c|c|}
\hline $\begin{array}{l}\text { Focus Group } \\
\text { Question }\end{array}$ & Participant 1 & Participant 2 & Participant 3 & Participant 4 & Participant 5 & Participant 6 \\
\hline $\begin{array}{l}\text { Participant } \\
\text { Selection }\end{array}$ & \begin{tabular}{|l|} 
Plan Nationale, the \\
Haitian subset of \\
PEPFAR, is in charge of \\
participant selection. \\
They select participants, \\
not SDH
\end{tabular} & $\begin{array}{l}\text { MSH (write out) also } \\
\text { sends names to Plan } \\
\text { Nationale, who are then } \\
\text { considered for } \\
\text { participation }\end{array}$ & $\begin{array}{l}\text { There have been } \\
\text { instances where local } \\
\text { doctors request to } \\
\text { participate and SDH } \\
\text { includes them as } \\
\text { substitutes }\end{array}$ & NR & NR & NR \\
\hline $\begin{array}{l}\text { Current } \\
\text { methods for } \\
\text { measuring } \\
\text { program } \\
\text { success }\end{array}$ & $\begin{array}{l}\text { A satisfaction survey is } \\
\text { sent out to all } \\
\text { participants upon } \\
\text { completion }\end{array}$ & $\begin{array}{l}\text { Agreed with participant } \\
1 .\end{array}$ & $\begin{array}{l}\text { The surveys have been } \\
\text { lost throughout the } \\
\text { years due to } \\
\text { administration changes. }\end{array}$ & $\begin{array}{l}\text { In addition, pre- and } \\
\text { post-test data is } \\
\text { collected in order to } \\
\text { evaluate success in } \\
\text { knowledge increase. }\end{array}$ & $\begin{array}{l}\text { Agreed with participant } \\
6 .\end{array}$ & $\begin{array}{l}\text { It is the responsibility of } \\
\text { the coordinator to } \\
\text { share the results with all } \\
\text { of the trainers as } \\
\text { feedback. }\end{array}$ \\
\hline $\begin{array}{l}\text { Keeping in } \\
\text { touch with past } \\
\text { participants }\end{array}$ & E-mail or telephone & E-mail or telephone & $\begin{array}{l}\text { Not involved with } \\
\text { participant contact. }\end{array}$ & No response & $\begin{array}{l}\text { E-mail or telephone, } \\
\text { but many participants } \\
\text { are lost to follow up }\end{array}$ & No response \\
\hline $\begin{array}{l}\text { Biggest } \\
\text { successes of } \\
\text { training } \\
\text { program }\end{array}$ & $\begin{array}{l}\text { SDH has seen a growth } \\
\text { in HIV/AIDS knowledge } \\
\text { among staff due to } \\
\text { program. Seen during } \\
\text { infectious disease } \\
\text { rounds primarily. }\end{array}$ & $\begin{array}{l}\text { There is now a stronger } \\
\text { referral system in place } \\
\text { that SDH and } \\
\text { surrounding hospitals in } \\
\text { Haiti can use. }\end{array}$ & $\begin{array}{l}\text { The program has } \\
\text { welcomed many } \\
\text { international staff, } \\
\text { visiting SDH for } \\
\text { research, to be guest } \\
\text { lecturers and provide } \\
\text { additional insight. }\end{array}$ & $\begin{array}{l}\text { Trainers are able to } \\
\text { travel to practical sites } \\
\text { with participants, which } \\
\text { facilitate an } \\
\text { environment of } \\
\text { collaboration. }\end{array}$ & $\begin{array}{l}\text { Participants are now } \\
\text { also more capable of } \\
\text { understanding the HIV } \\
\text { status of patients and } \\
\text { being able to provide } \\
\text { better all-around care. }\end{array}$ & $\begin{array}{l}\text { SDH hospital's HIV clinic } \\
\text { is now considered to be } \\
\text { one of the most } \\
\text { successful in the } \\
\text { country. }\end{array}$ \\
\hline $\begin{array}{l}\text { Areas for } \\
\text { program } \\
\text { improvement }\end{array}$ & $\begin{array}{l}\text { The length of the } \\
\text { program ( } 6 \text { weeks) is } \\
\text { too restrictive to learn } \\
\text { both general pediatrics } \\
\text { and HIV practice. This } \\
\text { means that there is less } \\
\text { time for practice. }\end{array}$ & $\begin{array}{l}\text { Scheduling has proven } \\
\text { to be a challenge, } \\
\text { because due to their } \\
\text { own patient duties, } \\
\text { some doctors are not } \\
\text { able to attend all } \\
\text { sessions of the } \\
\text { program. }\end{array}$ & $\begin{array}{l}\text { There have been } \\
\text { examples of budget } \\
\text { cuts and restrictions } \\
\text { that have caused the } \\
\text { program to run short. }\end{array}$ & $\begin{array}{l}\text { There needs to be some } \\
\text { revisions to the } \\
\text { structure of the } \\
\text { program to provide a } \\
\text { more well-rounded } \\
\text { educational experience } \\
\text { including practical and } \\
\text { clinical knowledge. }\end{array}$ & $\begin{array}{l}\text { It is not easy to select } \\
\text { the doctors to facilitate } \\
\text { the programs, because } \\
\text { then they have to get } \\
\text { coverage for their own } \\
\text { patients. }\end{array}$ & $\begin{array}{l}8 \text { weeks would be a } \\
\text { better length of time, } \\
\text { so that more topics and } \\
\text { practice can be } \\
\text { incorporated. }\end{array}$ \\
\hline $\begin{array}{l}\text { How often has } \\
\text { the program } \\
\text { curriculum } \\
\text { been revised }\end{array}$ & $\begin{array}{l}\text { It is currently in revision } \\
\text { by PEPFAR and Plan } \\
\text { Nationale. }\end{array}$ & $\begin{array}{l}\text { There is no standard of } \\
\text { revision, so this is a } \\
\text { tough thing to answer. }\end{array}$ & $\begin{array}{l}\text { SDH really doesn't have } \\
\text { control over content, } \\
\text { but we have discussed } \\
\text { changing schedule } \\
\text { structure in the past. }\end{array}$ & $\begin{array}{l}\text { Initially, revisions were } \\
\text { supposed to be every } 2 \\
\text { years, but this has not } \\
\text { happened. }\end{array}$ & $\begin{array}{l}\text { I think the program } \\
\text { should be revised every } \\
\text { year, but due to time } \\
\text { constraints it is often } \\
\text { overlooked. }\end{array}$ & $\begin{array}{l}\text { Not involved in } \\
\text { revisions, don't know } \\
\text { how it works. }\end{array}$ \\
\hline $\begin{array}{l}\text { Opportunities } \\
\text { for expanding } \\
\text { to online } \\
\text { modules }\end{array}$ & $\begin{array}{l}\text { This would be a great } \\
\text { opportunity, but given } \\
\text { the poor internet in } \\
\text { Haiti it seems like it } \\
\text { would be difficult. }\end{array}$ & $\begin{array}{l}\text { Our target is to work } \\
\text { with doctors who are } \\
\text { working with } \\
\text { underserved } \\
\text { populations, so they } \\
\text { may not have reliable } \\
\text { access to internet. }\end{array}$ & $\begin{array}{l}\text { This is something that } \\
\text { would be great in } \\
\text { several years, but the } \\
\text { current internet } \\
\text { capacity in the country } \\
\text { makes this difficult. }\end{array}$ & $\begin{array}{l}\text { Maybe some material } \\
\text { could be pre-recorded } \\
\text { for participants to be } \\
\text { used for their own } \\
\text { studying, but we would } \\
\text { rather focus on } \\
\text { in-person learning. }\end{array}$ & $\begin{array}{l}\text { This would not work in } \\
\text { Haiti, there is no strong } \\
\text { internet without a high } \\
\text { cost. }\end{array}$ & $\begin{array}{l}\text { We would have to } \\
\text { guarantee a strong } \\
\text { internet connection, } \\
\text { which in this country is } \\
\text { nearly impossible and } \\
\text { also very expensive. }\end{array}$ \\
\hline
\end{tabular}

Table 5B: Frequencies of survey responses to questions of program modalities.

\begin{tabular}{|l|l|l|}
\hline & Frequency & Percent \\
\hline Lecture module preference & & \\
\hline Computer-based & 4 & $22.2 \%$ \\
\hline In-person & 11 & $61.1 \%$ \\
\hline Published lectures & 3 & $16.7 \%$ \\
\hline Learning methods preferences & & \\
\hline Case-based learning & 3 & $13 \%$ \\
\hline Formal lecture & 6 & $26.1 \%$ \\
\hline Hands-on learning, practical & 4 & $17.4 \%$ \\
\hline Online learning modules & 5 & $21.7 \%$ \\
\hline Small group learning & 5 & $21.7 \%$ \\
\hline $\begin{array}{l}\text { Would you be interested in an advanced HIV } \\
\text { training program if it were offered? }\end{array}$ & & \\
\hline Yes & 14 & $100 \%$ \\
\hline No & 0 & 0 \\
\hline
\end{tabular}




\section{Discussion}

This study utilized three main data sources to evaluate the HIVTP: survey responses, program test data, and focus group responses. The HIVTP was successful in increasing human resources for pediatric HIV care in Haiti. While this study is limited by a single site, and low response rate, a response rate of $33 \%$ is consistent with the average response rate of physicians for self administered surveys [9]. With 79\% of the respondents still caring for HIV patients within their practice, this demonstrates good utility of the HIVTP. Analyzing the available pre- and post-test data suggests that the academic structure of the program is well integrated, with a positive increase in pediatric HIV knowledge throughout the program. The focus group discussion with program administrators and facilitators reflected on a hesitation in moving towards computer or online modules due to poor internet access throughout the country.

The distribution methods of the surveys should be reconsidered in order to increase physician response rates (online versus paper completion, e-mail versus mail return). A limitation of this study with regards to generalization to other training programs is that this study evaluated a single site, and future researchers should cast a broader net to collect data from HIV training programs across multiple resource limited settings. Given the response rate it is possible to have over-estimated the percentage of those providing HIV care as respondents active in pediatric HIV care were more likely bias to respond due to active participation in pediatric HIV care. The training program was successful in drawing participants from seven of Haiti's ten regions. The regions most represented were the Nord and the Sud, showing that the training program did reach beyond the Ouest region where SDH is located. The Nord region of Haiti has the highest prevalence of HIV in the country, so it was essential that a high percentage of participants came from this region. Questions regarding the range of number of patients seen by graduates of the HIVTP provided a window into approximately how many HIVinfected individuals were reached by the program. About $40 \%$ of the participants see infants/children, adolescents, adults, and pregnant women in their clinics. This shows that it was a successful strategy for the training program to target general physicians in order to reach more pregnant women, children, and to foster family-centered care (providers care for both mothers and children with HIV). However, future research into the efficacy of pediatric training programs should also utilize geographical mapping software in order to properly map the expansion of care proved. While we don't know the exact number of patients reached, if we assume that each of the positive 11 respondents on average cares for 100 patients with HIV, then we can roughly estimate the respondents provide care to approximately 1,100 individuals with HIV. Given there are no publications in the medical literature on such program outcomes, this single-site evaluation does offer some meaningful information for program funders, directors, and future participants.

Another measure of program utility was the percentage of patients seen by participants that are currently on ART, broken down into two groups: pregnant women and children. Of the 14 program respondents, the majority reported that more than $75 \%$ of the eligible pregnant women in their clinics were on ART. This shows a grasp of the knowledge of PMTCT and the importance of proper ART regimens, particularly given that mother to child transmission is the most prevalent mode of pediatric HIV transmission. The results of whether or not eligible children were on ART, however, were less satisfactory. Of the 14 respondents only 38\% reported that more than $75 \%$ of the eligible children in their clinic were on ART. Of the surveyed participants, 50\% reported that less than $9 \%$ of the eligible children being seen in their clinics were on ART. Improving the number of eligible pediatric patients placed on ART will require re-evaluation by program administrators, this includes: evaluating access to essential medications, further training on the program, and reducing any potential cost barriers to providing proper ART treatment. The survey responses, however, could be a reflection of difficulty in understanding the questions posed to participants. The questions regarding percentage of eligible pregnant women on ART and percentage of eligible pediatric patients on ART were worded in the same way, yet the rates were disparate. This suggests the respondents likely understood the questions; however, despite researchers having the questions read for meaning by three separate native speakers, there could be a role for future surveys to be worded more clearly. More careful wording of the survey questions about rates of eligible patients on ART must be considered in order to reflect the total number of eligible patients receiving ART. This could help to achieve a more accurate representation. Future survey tools could be tested before use to assess the need for more clarifying follow-up questions, including barriers to pediatric care.

Participants were also asked whether or not they treated TB in their clinics, due to the fact that it is a common opportunistic co-infection among those with HIV and there are significant drug interactions when treating both infections. Of the HIVTP participants, $43 \%$ reported that they treat TB, which suggests that future training programs should more clearly highlight the importance of recognizing and treating HIV/TB co-infections and address the nuances of TB and ART drug interactions. A limitation to the survey design could be in the phrasing of the question: "Do you treat patients with Tuberculosis?" Participants either do not see TB patients, don't recognize HIV/TB co-infection, or they don't feel comfortable treating TB. Expanding on the question phrasing could have provided more insight into why more than half of the respondents do not currently treat TB. In 2010, Haiti developed a national protocol for the management of TB in children that was not specifically addressed by the survey, and post-dates the start of the HIVTP. It is possible that a response of $43 \%$ may be appropriate if physicians who only see a few patients do not see TB in their patients. Future researchers can continue to focus on HIV/TB coinfection by asking more clarifying and follow-up questions. The HIVTP had an overall trainee satisfaction rate of $86 \%$, measured based on responses to 
topic coverage. This indicates that participants were generally satisfied with their experiences and enjoyed the training program content and structure. Additional measures of trainee satisfaction were whether or not participants felt prepared to take care of their own pediatric HIV patients following the program and whether or not they felt prepared to teach pediatric HIV care practices to members of their own teams. Of the 14 participants, $79 \%$ indicated that they felt "absolutely prepared" to take care of their own pediatric HIV patients, whereas $21 \%$ indicated that they felt "somewhat prepared." Importantly, zero participants reported feeling "unprepared." This suggests that participants may benefit from more time spent with hands on clinical practice, and to increase preparedness. Although recall bias must be considered when asking these questions so far out from program completion, it is important to note that $79 \%$ felt "absolutely prepared" after some time out from the HIVTP. Additionally, $100 \%$ of the participants felt "somewhat prepared" to teach pediatric HIV care practices to members of their own clinics, which indicates an area for improvement, as well as opportunity, in the program design. Participants should feel prepared to teach members of their team proper HIV care in order to expand the continuum of pediatric HIV care. Of the 14 participants, $100 \%$ indicated that they would be interested in an advanced training course on pediatric HIV, which could be integrated into a task shifting model that would extend.

\section{Conclusion}

With HIV infection rates continuing to rise in many resource-limited nations, particularly among children, it is essential to train a cadre of physicians, nurses, and other health professionals to manage caseloads. This study serves as a foundation for further research to be performed on the utility of physician training programs in Haiti and other resource-constrained settings to increase the human resource pool for pediatric HIV care. The HIVTP was successful in creating at least 11 graduates from seven of the ten regions of Haiti who continue to provide in-country HIV care. Utilizing these successful HIVTP graduates to create a network and infrastructure for future training programs and pilot projects would create more opportunity to provide universal access and decentralization of pediatric HIV care. The successes and barriers identified in this study, such as program length, modality, and topic coverage, should be used in the development and evaluation of future physician and allied care training programs. Although this particular study focused only on the training of physicians, it could be replicated and modified to include any allied healthcare professional. In particular, it is suggested that better records be kept on all participants in order to facilitate a more accurate evaluation process and improve post-training communication. Training programs have an important future in the decentralization of pediatric HIV care and the HIVTP model provides the foundation for expansion.

\section{Conflicts of Interest}

The authors declare no conflicts of interest with this submission.

\section{Consent}

Participants has provided written consent for publication of this work.

\section{Acknowledgments}

This work was funded by Brown University Framework Grant.

\section{References}

1. Green A, de Azevedo V, Patten G, Davies MA, Ibeto M, Cox V. Clinical mentorship of nurse initiated antiretroviral therapy in khayelitsha, South Africa: a quality of care assessment. PloS one. 2014; 9: e98389. doi: 10.1371/journal.pone.0098389

2. Abrams EJ, Simonds RJ, Modi S, et al. PEPFAR scale-up of pediatric HIV services: innovations, achievements, and challenges. J Acquir Immune Defic Syndr. 2012; 60: S105-S112. doi: 10.1097/QAl.0b013e31825cf4f5

3. United States President's Plan for Emergency AIDS Relief. All countries partner and sub-partner counts by local status, organization type, and program area, 2009.

4. Center for Disease Control: Women, Children, and HIV. Guide to implementation of services for early infant diagnosis in resource-limited settings. 2009.

5. Fayorsey RN, Saito S, Carter RJ, et al. Decentralization of pediatric $H N$ care and treatment in five sub-Saharan African countries. J Acquir Immune Defic Syndr. 2013; 62: e124-e130. doi: 10.1097/QAl.0b013e3182869558

6. Kimmel AD, Charles M, Deschamps MM, et al. Lives saved by expanding HIV treatment availability in resource-limited settings: the example of Haiti. J Acquir Immune Defic Syndr. 2013; 63: e40-e48. doi: 10.1097/ QAI.0b013e3182918875

7. WHO. Global health observatory data repository, country-specific statistics, Haiti. 2012.

8. George E, Noel F, Bois G, et al. Antiretroviral therapy for HIV-1-infected children in Haiti. J Infect Dis. 2007; 195: 1411-1418. doi: 10.1086/514823

9. TImothy S Flanigan, Emily McFarlane, Sarah Cook. Conducting survey research among physicians and other medical professionals - A review of current literature. American Association for Public Opinion Research. 2008; Section on Survey Research Methods: 136-4147. 